\title{
ICS standaard: goed uitvoeren van urodynamisch onderzoek
}

\author{
Peter F. W. M. Rosier ${ }^{1}$ \\ Published online: 6 February 2018 \\ (c) The Author(s) 2018. This article is an open access publication.
}

\section{Samenvatting}

In juni 2017 is in Neurourology and Urodynamics de nieuwe International Continence Society (ICS)-standaard voor het goed uitvoeren van urodynamisch onderzoek gepubliceerd. Dit artikel is een Nederlandstalige samenvatting daarvan. De standaard is geïnitieerd door de Stuurgroep Standaardisatie van de ICS en opgesteld door een ad-hocwerkgroep, bestaande uit Werner Schaefer; Gunnar Lose; Howard B Goldman; Michael Guralnick; Sharon Eustice; Tamara Dickinson; Hashim Hashim en Peter Rosier.

Trefwoorden praktijkstandaard en kwaliteit · richtlijn · cystometrie · incontinentie $\cdot$ LUTS · druk-flowstudie · urodynamica $\cdot$ uroflowmetrie

\section{ICS standard: well performed urodynamic research}

\begin{abstract}
In June 2017, in Neurourology and Urodynamics, the new ICS standard for good urodynamic practices was published. This article is the Dutch translation. This standard has been developed by an ad hoc working group, steered by the ICS Standardisation Steering Committee, with Werner Schaefer, Gunnar Lose, Howard B Goldman, Michael Guralnick, Sharon Eustice, Tamara Dickinson, Hashim Hashim and Peter Rosier.
\end{abstract}

Keywords clinical practice standard and quality $\cdot$ cystometry $\cdot$ incontinence $\cdot$ lower urinary tract dysfunction $\cdot$ pressure-flow study $\cdot$ urodynamic $\cdot$ uroflowmetry

\section{Introductie}

De stuurgroep standaardisatie van de ICS heeft een werkgroep (WG) geïnstalleerd om de bestaande International Continence Society's Good Urodynamic Practices uit 2002 (de GUP2002) te updaten [1]. Nieuw wetenschappelijk bewijs en nieuwe informatie betreffende de praktijk van urodynamisch onderzoek en kwaliteitscontrole, alsmede de vernieuwde ICS-standaard voor urodynamische apparatuur maakte de update nodig en nuttig [2]. De GUP2016 is opgesteld volgens het ICS-standaardisatieproces [3]. In het originele document is beargumenteerd en aangegeven waar

dr. Peter F. W. M. Rosier

p.f.w.m.rosier@umcutrecht.nl

1 afdeling Urologie, Universitair Medisch Centrum Utrecht, Utrecht, Nederland wijzigingen in de termen of de uitvoering zijn aanbevolen [4].

Veel termen bij urodynamisch onderzoek zijn impliciet gebruikt in de eerdere standaardisaties, zonder een precieze definitie. In de praktijk en in de wetenschappelijke literatuur, maar ook in teksten voor leken, wordt een flink aantal synoniemen gebruikt voor urodynamische tests en de WG concludeerde dat het gebruik van de bestaande standaardterminologie in de wetenschappelijke literatuur nog suboptimaal is. Behalve termen voor tests, heeft de WG ook de termen voor observaties op basis van het onderzoek gestandaardiseerd en zijn nu ook standaarden gedefinieerd voor vooraf te verstrekken informatie en voor verslaglegging.

Deze samenvatting is een opsomming van de belangrijkste definities en aanbevelingen uit het ICS-document, in het Nederlands vertaald. Veel Engelse termen zijn in Nederland ingeburgerd, en niet vertaald, hoewel er in deze samenvatting vaak wel een vertaling voor wordt gegeven. Voor het wetenschappelijke bewijs van, en de argumentatie inzake de 
aanbevelingen wordt in deze samenvatting verwezen naar het oorspronkelijke document [4].

\section{Termen}

Met het oog op uniformiteit van verslaglegging, in de klinische setting, maar met name ook ten behoeve van wetenschappelijk onderzoek, worden de volgende termen als (nieuwe) ICS-standaard voorgesteld.

\section{Urodynamisch onderzoek}

De algemene term voor een meting die de bedoeling heeft de functie en disfunctie van de lage urinewegen (lower urinary tract $=$ LUT) te beoordelen. Urodynamisch onderzoek makkt objectieve beoordeling van LUT-functie mogelijk, door meting van relevante fysiologische parameters (ongewijzigd t.o.v. de GUP2002 [1]).

\section{Invasief urodynamisch onderzoek}

Een test is invasief, als ten behoeve van het (urodynamisch) onderzoek één of meer katheters of andere voorwerpen (naald/sonde/probe etc.) in de blaas en/of andere lichaamsholte(n) wordt ingebracht.

\section{Niet-invasief urodynamisch onderzoek}

Elk urodynamisch onderzoek dat gedaan wordt zonder het inbrengen van materiaal in lichaamsholte(n): bijvoorbeeld uroflowmetrie, residumeting, penis compressie-releasetest, penismanchet, condoomkatheter-druktest of (niet-inwendige) echografie.

\section{Ambulant urodynamisch onderzoek}

In deze standaard wordt ambulant urodynamisch onderzoek niet verder besproken (ook niet in de oorspronkelijke versie). Er wordt verwezen naar de specifieke ICS-standaard.

\section{ICS Standaard urodynamische test (ICS-SUT) (nieuw)}

Deze test bestaat uit opeenvolgend uitgevoerde uroflowmetrie en residumeting plus transurethrale cystometrie en druk-flowstudie (met residumeting). Alle tests worden uitgevoerd in de meest gebruikelijke of de voorkeurspositie van de patiënt; comfortabel zitten, en/of staan - tijdens de mictie -, als dat fysiek mogelijk is. Als de patiënt al deze onderzoeken heeft gehad, kan vermeld worden (vooral van belang voor een cohort in een wetenschappelijke studie) dat er een ICS-SUT is gedaan.

\section{ICS Standaard urodynamisch protocol (ICS-SUP) (nieuw)}

Van (iedere) patiënt wordt gerapporteerd: de klinische voorgeschiedenis, met (minimaal) één gevalideerde symptoomen hinderscore (en een medicatielijst); relevant klinisch lichamelijk onderzoek; een drink-plasdagboek en een volledige ICS-SUT (zie hiervoor). Bij rapportage van al deze onderzoeken kan vermeld worden (vooral van belang voor een cohort in een wetenschappelijke studie) dat een ICSSUP is gedaan.

\section{Aanvullende tests}

Een ICS-SUT kan worden aangevuld met een elektromyogram (EMG), met beeldvorming, met continue urethrale drukmeting(en) en/of met bijvoorbeeld meting(en) van een urethradrukprofiel. Cystometrie kan worden gedaan via een suprapubische katheter (specificeer in wetenschappelijk cohorten bij aanvullende tests ook de methode die is gebruikt).

\section{Aanbeveling ICS-tests}

The WG stelt voor om in ieder geval de ICS-SUT - en bij voorkeur - de volledige ICS-SUP-gegevens samen te vatten voor de totale groep patiënten in de beschrijving van alle wetenschappelijke cohorten die invasief-urodynamische resultaten bevatten.

Bovendien suggereert de WG, indien ICS-SUT- of SUPgegevens worden gerapporteerd, te verwijzen naar het manuscript (de ICS-GUP2016) [4], wanneer onderzoek wordt gemeld als "... uitgevoerd volgens de 'ICS-standaard Goed uitvoeren van Urodynamisch Onderzoek"”.

\section{Uroflowmetrie}

Een test die (citaat GUP2002 [1]): '.. het debiet van de externe urinestroom meet, als volume per tijdseenheid in milliliters per seconde $(\mathrm{ml} / \mathrm{s})^{\prime}$. Van een uroflowmetrie worden in ieder geval het maximale debiet (maximale flowrate $\left(\mathrm{Q}_{\max }\right)$ ), het volume en het residu vastgelegd. (ongewijzigd t.o.v. GUP2002 [1].) Andere kenmerken, zoals het patroon van de flowrate op de tijdas en andere parameters, mogen worden toegevoegd. In wetenschappelijke rapporten moeten deze andere kenmerken specifiek gedefinieerd worden.

\section{Residu na mictie (kort: Residu) [1]}

Het resterend volume in de blaas, het residu, dat is bepaald direct na voltooiing van de mictie. De techniek (echografie of katheter) die is gebruikt voor het meten van het residuvolume moet worden opgegeven. 
De WG suggereert als nieuwe ICS-standaardparameter: het mictiepercentage. De numerieke beschrijving van de effectiviteit van de mictie, weergegeven als het deel van de inhoud van de blaas dat is geleegd in procenten. Berekening: ((volume geplast/(volume geplast + residu $) \times 100)$. De WG suggereert de afkorting mictie\%. De relevantie van deze parameter - in klinisch of wetenschappelijk verband - wordt hier verder niet besproken.

\section{Cystometrie}

Continue vulling van de blaas met vloeistof via een transurethrale (of andere route, bijvoorbeeld een suprapubische of Monti-/Mitrofanoff-) katheter, met ten minste intravesicale en abdominale drukmeting en weergave van detrusor(substractie)druk, met inbegrip van hoest(stress)tests. Cystometrie eindigt met 'verlof tot mictie' of met incontinentie van de totale inhoud van de blaas. Het soort vloeistof, de temperatuur, de methode en de snelheid van vullen, de kathetermaten, de drukregistratietechniek en de patiëntpositie moeten worden beschreven.

\section{Cysto-urethrometrie}

Cystometrie met continue meting van de urethrale druk (specificeer de gebruikte techniek).

\section{Druk-flowstudie}

De intravesicale en abdominale druk wordt gemeten, vanaf het moment van 'verlof tot mictie', terwijl uroflowmetrie wordt gedaan met een transurethrale (of suprapubische) katheter in situ. De positie van de patiënt, de kathetermaat en de methode van drukmeting en uroflowmetrie moeten worden beschreven.

\section{Bekkenbodemspier-EMG}

Bekkenbodemspieractiviteit wordt beoordeeld met oppervlakte-elektrodes. De ICS-standaard luidt als volgt: De twee elektroden op de perineale huid met als referentie een $\left(3^{\mathrm{e}}\right)$ neutrale - niet op een spier - elektrode. Andere (invasieve) EMG-typen - niet standaard tijdens urodynamisch onderzoek - worden bijvoorbeeld uitgevoerd met een probe: 'vaginale EMG', 'anale EMG', 'naald-EMG', etc. Het aantal en de positie van de elektrode(n) moeten specifiek worden gerapporteerd.

\section{Urethra drukprofiel}

Zie de ICS-standaard voor meting van de urethrale druk.

\section{Video-urodynamisch onderzoek}

Urodynamisch onderzoek kan worden gecombineerd met beeldvorming: cystometrie en of druk-flowstudie, uitgevoerd met contrastvloeistof als vullingsmedium en synchrone röntgendoorlichting. Hierbij worden röntgen (beeldversterker) afbeeldingen of cinelussen op relevante momenten vastgelegd, en gekoppeld aan de urodynamische (drukflow)data weergegeven. De totale stralingsdosis per patiënt en het gebruikte contrastmedium moeten worden vastgelegd. Video-urodynamisch onderzoek wordt verder in deze standaard niet besproken (ook niet in de oorspronkelijke versie).

\section{Informatie voor de patiënt en voorbereiding van de patiënt voor invasief urodynamisch onderzoek}

De WG beveelt aan dat iedere patiënt die een urodynamisch onderzoek zal krijgen een folder ontvangt die de punten uit tab. 1 op een begrijpelijke manier uitlegt: Een folder waarin alle punten uit tab. 1 zijn opgenomen, wordt aangeduid als een ICS Standaard Informatiefolder voor Urodynamisch onderzoek (tab. 1).

\section{Urodynamische praktijk}

De WG heeft aanbevolen dat afdelingen specifieke protocollen ontwikkelen voor de urodynamisch praktijk, op basis van de ICS-GUP-normen. We WG heeft ook geadviseerd dat specifieke opleiding voor het uitvoeren van urodynamisch onderzoek, en (kwaliteits)evaluatie van praktijken en centra, op een landelijk niveau gecoördineerd wordt.

Verder adviseert de WG dat er definiëring plaatsvindt van individuele accreditatie en certificering (bijvoorbeeld het vereiste minimumaantal gecontroleerd uitgevoerde tests) en het niveau van autonomie voor het verrichten van (delen van het) urodynamisch onderzoek, met inachtneming van lokale regelgeving [6].

\section{Klinische informatie voor het onderzoek}

De WG adviseert dat, afgezien van de klinische informatie zoals aanbevolen in de richtlijnen voor de klinische praktijk (anamnese, ziektegeschiedenis, medicijngebruik en klinisch onderzoek), de informatie van het drink-plasdagboek, de uroflowmeting en het residu worden gebruikt tijdens het uitvoeren van invasief urodynamisch onderzoek.

De WG adviseert ook specifieke geïndividualiseerde instructies aan de patiënt te verstrekken ten aanzien van het 
Tabel 1 Schematisch overzicht van de inhoud van een ICS Standaard Informatiefolder voor Urodynamisch onderzoek

Wat is een urodynamisch onderzoek?

- Het onderzoek houdt in dat katheters ingebracht worden in de blaas en het rectum.

- Benoem andere relevante zaken, als EMG wordt gebruikt, als urethradruk wordt gemeten etc.

Wat is het nut van urodynamisch onderzoek

- Waarom wordt het - in het algemeen - gedaan?

Wat zijn de verschillende stappen van een urodynamisch onderzoek en hoe worden ze uitgevoerd?

- Bijvoorbeeld uroflowmetrie, cystometrie, meting van de urethrale druk en druk-flowstudie

Hoe waardigheid, comfort en communicatie tijdens het onderzoek worden gemaximaliseerd

- Wat wordt gedaan of geboden in dit verband

Welke symptomen na het onderzoek kunnen optreden, wat ze betekenen en hoe ze kunnen worden behandeld of voorkomen

- Bijvoorbeeld het feit dat mild ongemak, frequentie, dysurie en hematurie kunnen worden ervaren, en zich een blaasontsteking kan ontwikkelen.*

Aanvullende informatie, met inbegrip van:

- de duur van het onderzoek;

- de steriliteit van relevante delen van apparatuur;

- afwezig zijn van 'injecties' of medicijnen

Dat de test interactief wordt verricht en dat communicatie met de patiënt, en samenwerking, noodzakelijk zijn

Wat de patiënt vóór het onderzoek moet doen

- Bijvoorbeeld, indien mogelijk, met een volle blaas arriveren, en met een lege darm

Of de patiënt de voor haar of hem gebruikelijke medicijnen vóór het onderzoek moet blijven nemen, of dat er specifieke (urologische of niet urologische) medicijnen zijn die de patiënt niet meer moet nemen (een gedefinieerde periode) voorafgaande aan het onderzoek.

- Opmerking: Dit moet worden geïndividualiseerd, bijvoorbeeld met aankruisen, of een schriftelijke instructie van de aanvrager

Wat de patiënt moet doen na de test

- Bijvoorbeeld: onmiddellijk 0,5-1 L extra vloeistof drinken, voor en direct na de meting een paar keer extra plassen, ter verlichting van de irritatie van de urethra

Dat gewoonlijk alle gebruikelijke activiteiten zijn toegestaan na de test

Beschrijf: symptomen en tekenen van blaasinfectie en welke stappen te nemen als deze zich voordoen

*Overweeg (ook afhankelijk van de lokale situatie en regels) om een lijst te includeren met 'risico's en bijwerkingen waarvan een redelijk geïnformeerde patiënt op de hoogte zou moeten zijn'

continueren of stopzetten van de voor de patiënt gebruikelijke LUT- (of andere) medicatie, bijvoorbeeld als de patiënt tijdens de medicamenteuze behandeling aanhoudende of nieuwe klachten heeft of als een nieuw onderzoek wordt verricht voor een chronische disfunctie of aandoening.

De ICS-GUP heeft opgenomen dat routine antibiotische profylaxe en of laxantia specifiek voor het (invasief) urodynamisch onderzoek niet tot de standaard behoort.

\section{Praktijk van de uroflowmetrie}

De WG beveelt aan om uroflowmetrie uit te voeren in de door de patiënt aangegeven voorkeurspositie en daarbij te streven naar minimaal fysiek ongemak. Privacy en persoonlijke waardigheid moeten zo veel mogelijk worden gewaarborgd. Als de patiënt na de meting aangeeft dat de meting niet representatief was of als het geplaste volume niet in overeenstemming is met wat verwacht wordt, eventueel op basis van de volumes in het mictiedagboek van de patiënt, moet de meting als zodanig worden beoordeeld en in het dossier vastgelegd.

De positie van de patiënt tijdens de mictie moet worden gerapporteerd en de WG adviseert herhaling van de uro- flowmetrie als het resultaat niet representatief is geweest of (ter bevestiging) als het resultaat afwijkend is van de normale mictie.

\section{Praktijk van de cystometrie}

Cystometrie wordt verricht zoals beschreven in de GUP2002. Deze GUP2016 heeft zes aanbevelingen toegevoegd aan de GUP2002.

\section{(1) Wat bepaalt de vulsnelheid bij cystometrie?}

De WG beveelt aan dat de persoon die de cystometrie verricht, voorafgaand aan het onderzoek, op basis van de resultaten van het mictiedagboek, de uroflowmeting en het vastgestelde residu, een inschatting maakt van de voor de betreffende patiënt gebruikelijke blaascapaciteit. De WG suggereert dat de vullingssnelheid vervolgens wordt gestandaardiseerd op $\pm 10 \%$ van deze geschatte capaciteit per minuut (met inbegrip van de schatting van het residu), om te voorkomen dat te snel en/of tot een te groot volume wordt gevuld. 
Figuur 1 Fixatie van de transurethrale katheter. a Bij de man, b Bij de vrouw
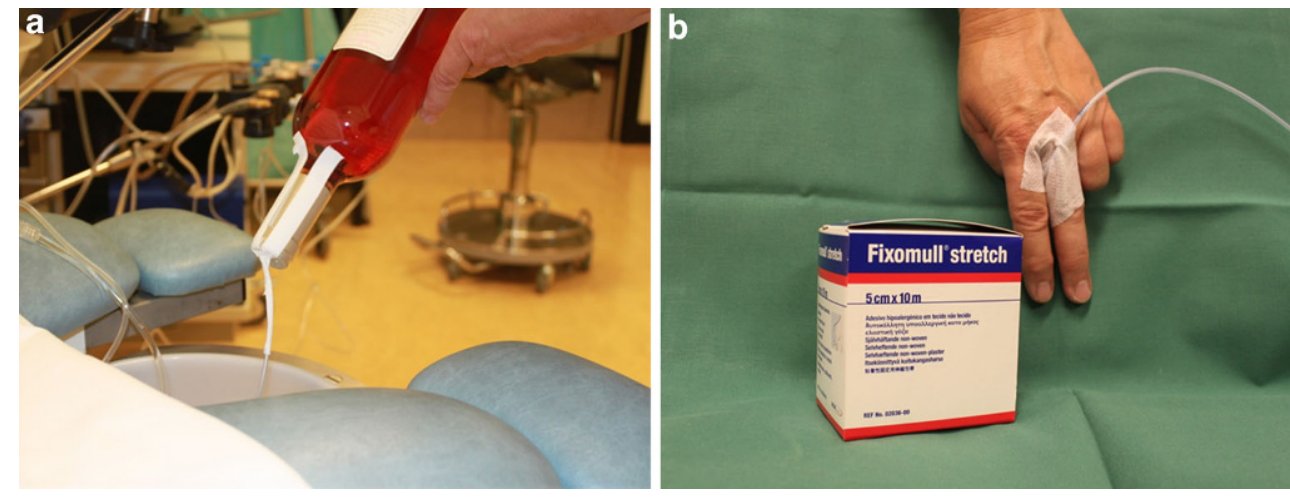

Parameters op basis van de cystometrie, die afhankelijk zijn van het (intravesicaal) volume, moeten worden gecorrigeerd voor diurese (achteraf), indien dat relevant is voor de behandeling of voor wetenschappelijke rapportage.

De WG beveelt aan dat 'verlof tot mictie' altijd moet worden gemarkeerd in de urodynamische grafiek. Verlof tot mictie markeert het einde van de opslagfase en het begin van de druk-flowstudie.

\section{(2) Hoe wordt de patiënt geïnstrueerd om blaasvullingssensatie(s) te rapporteren?}

De ICS Standardisation of Terminology, de ST2002 [5] beveelt aan dat er drie sensatieparameters worden vastgelegd tijdens cystometrie, namelijk: 1) eerste gevoel van blaasvulling (gebruik afkorting FSF: first sensation of filling); normale, eerste drang om te plassen (gebruik afkorting FDV: first desire to void) en sterke drang om te plassen (gebruik SDV: strong desire to void) [5]. Daarnaast kan de patiënt plotseling - en tijdelijk - sterk toenemende drang rapporteren. Dat kan worden gemarkeerd als 'urge' of 'urgency' (ST2002) [5] en specifiek in het verslag worden opgenomen.

FSF moet, aan het begin van de cystometrie, worden onderscheiden van de (urethrale) sensaties die veroorzaakt zijn door het katheteriseren, die gewoonlijk al snel wegzakken. De ICS-gestandaardiseerde uitleg aan de patiënt voor de eerste sensatie van vullen, vindt plaats na de start van de vulling en luidt: ("De blaas wordt nu door de nieren en door het urodynamicasysteem gevuld en ..."). “... Vertel me het moment wanneer u waarneemt dat de blaas niet leeg meer is."

Voor FDV kan gevraagd worden: "Vertel me wanneer u het gevoel hebt waarmee $\mathrm{u}$ normaliter naar het toilet zou gaan, zonder enige haast, als het goed uitkomt." FDV is (als er weinig of geen chronisch residu bestaat) meestal, maar niet altijd (!), ongeveer in overeenstemming met de volumes in het mictiedagboek.

SDV is dan vervolgens: "Het moment dat $\mathrm{u}$, zonder pijn of angst voor het verlies van urine, toiletbezoek niet meer zal uitstellen; u bezoekt het dichtstbijzijnde toilet, ook bijvoorbeeld tijdens het winkelen." SDV kan echter ook plotseling optreden (al dan niet met FDV), en de vrees voor verlies (of werkelijk urineverlies) inhouden. SDV met een gevoel van dreigend verlies, of met verlies, wordt specifiek vastgelegd.

Uiteraard moeten pijn en/of andere gewaarwording tijdens (en/of dóór) het vullen worden vastgelegd.

\section{(3a) Vloeistofgevuld(e) extern(e) druktransducers en kathetersysteem}

ICS-standaardcystometrie wordt uitgevoerd met vloeistofgevulde katheters en verbindingsslangen met externe drukregistratie (transducers), die op het niveau van de bovenste rand van de symphysis pubica zijn gebracht.

Urodynamische laboratoria moeten ervoor zorgen dat de uitrusting, met inbegrip van de katheters en de druk- en flowtransducers, voldoet aan de eisen die zijn vastgelegd in de ICS-standaard voor urodynamische apparatuur [2].

Urodynamische laboratoria moeten de prestaties van hun systeem met vaste tussenpozen controleren en kalibreren conform de aanbevelingen van de fabrikant, en zoals geadviseerd in de ICS-standaard voor urodynamisch apparatuur [2].

\section{(3b) Transurethrale katheter}

Invasief urodynamisch onderzoek volgens de ICS-standaard wordt (op basis van de GUP2002 [1] en de ST2002 [5]) gedaan met de dunst mogelijke (6F of $7 F$ ) transurethrale dubbel- of driedubbel-lumenkatheter of via een suprapubische katheter. De WG raadt aan om de katheters met tape te fixeren, zo dicht mogelijk langs, of op de anus, en vlak naast de urethrale meatus, zonder dat de urine-uitgang wordt geblokkeerd (fig. 1). 


\section{(4) Abdominale drukmeting: rectale versus vaginale katheterplaatsing}

De ICS-standaard voor het meten van abdominale druk omvat intrarectale plaatsing van een volledig met vloeistof gevulde open katheter of plaatsing van een met vloeistof gevulde katheter met een geperforeerde ballon.

De WG beveelt aan dat vaginale of stomaplaatsing van de abdominale drukkatheter alleen gebruikt wordt als rectale katheterplaatsing niet mogelijk is.

\section{(5) Patiëntpositionering voor cystometrie en druk- flow}

ICS-standaardcystometrie gebeurt in de verticale positie (zittend of staand) als dat fysiek mogelijk is. Een drukflowstudie wordt (bij vrouwen en sommige mannen) zo comfortabel mogelijk zittend gedaan of staand als dat de voorkeurspositie (mannen) is.

\section{(6) Betrouwbaarheid, en direct herhaalde cystometrie ter bevestiging}

De WG adviseert geen routinematige onmiddellijke herhaling van invasief urodynamisch onderzoek 'ter bevestiging' als de test technisch voldoende of goed was, als deze test wordt beschouwd als representatief en als de test de klinische vraag beantwoord heeft.

De WG beveelt wél onmiddellijke herhaling van de test aan wanneer er twijfel bestaat over de vraag of de test de klinische vraag heeft beantwoord.

De WG raadt ook onmiddellijke herhaling van het urodynamisch onderzoek aan als technische fouten en/of artefacten zijn waargenomen.

\section{Praktijk van druk-flowstudies en een update van termen}

De WG beveelt aan, vooral met het oog op de druk-flowanalyse, om een zo kort mogelijke afstand tussen de meatus en de flowmeter re realiseren. De hoogte van de flowmeter (opvangtrechter) moet dus individueel worden aangepast aan de grootte en positie van de patiënt.

De druk-flowstudie moet worden weergegeven in een druk-flowgrafiek, met de flowdebiet $(\mathrm{mL} / \mathrm{s})$ op de $\mathrm{x}$-as en de (voor vertraging gecorrigeerde) synchrone detrusordruk $\left(\mathrm{cmH}_{2} \mathrm{O}\right)$ op de $\mathrm{y}$-as, als aanvulling op de op tijd ( $\mathrm{x}$-as) gebaseerde grafieken van druk en flow, zoals aangegeven in de ST1997 [7].

\section{Blaasuitstroomobstructie (nieuw)}

De termen blaasuitgangsobstructie en blaasuitstroomobstructie zijn al vaak gebruikt. De WG introduceert de term 'blaasuitstroomobstructie' (bladder outflow obstruction; BOO) ('uitstroom' om te herkennen wat is gemeten), en definieert dit als 'een mictie met een gespecificeerde afkapwaarde van blaasuitstroomweerstand, op basis van de druk-flowverhouding, die als klinisch relevant wordt beschouwd'. (De WG geeft geen afkapwaarde, maar adviseert de term blaasuitstroomobstructie voor zowel mannen als vrouwen en voor alle leeftijden.)

\section{Normale mictiefunctie (nieuw)}

De WG stelt normale mictiefunctie voor (Ned.: 'normale ontledigingsfunctie') als de 'flowdebiet (en de drukstijging) binnen normale grenzen zijn en de flow min of meer direct na toestemming om te plassen begint, en eindigt met een lege blaas'.

\section{Situationeel onvermogen om te plassen en situationeel onvermogen om te plassen zoals gewoonlijk (nieuw)}

Dit is de situatie waarin de persoon die de test uitvoert van mening is, in overleg met de patiënt, dat de poging tot mictie niet tot een representatief resultaat heeft geleid. Deze term wordt gebruikt voor zowel uroflowmetrie als een druk-flowstudie.

\section{Detrusor mictiecontractie}

De WG introduceert de term 'detrusor mictiecontractie' voor een kwantitatieve of kwalitatieve analyse van gecombineerde druk en flow (met of zonder andere variabelen) van de waargenomen mictiecontractie.

\section{Detrusorcontractiliteit}

Detrusorcontractiliteit wordt nu voorgesteld voor een methode die is gericht op het kwantificeren van de 'afgeleide intrinsieke' detrusorspiereigenschappen (bijvoorbeeld potentiële - maximale - kracht, of snelheid). De WG verwijst hiervoor naar bijvoorbeeld stop-flowtesten, maar ook naar wiskundige (extrapolatie) of grafische analysemethoden van druk, flow en/of andere parameters, zoals de indeling in de druk-flowgrafiek of de bladder working function. 


\section{Technische en klinische kwaliteitscontrole tijdens invasief urodynamisch onderzoek}

De WG raadt aan dat iedereen die urodynamisch onderzoek uitvoert of beoordeelt, deskundig is, de gebruikelijke drukpatronen herkent en continue kwaliteitscontrole uitvoert tijdens en na de test. De WG geeft ook aan dat specifieke opleiding en een proces van continue kennisverbetering de basis moeten zijn voor het uitvoeren van urodynamisch onderzoek.

\section{Aanbevolen termen voor het beschrijven van de meest voorkomende observaties, artefacten en fouten tijdens invasief urodynamisch onderzoek}

\section{Initiële rustdruk (nieuw)}

Dit is de $\mathrm{p}_{\mathrm{ves}}$ - en de $\mathrm{p}_{\mathrm{abd}}$-druk aan het begin van de cystometrie. Om te voorkomen dat de initiële rustdruk wordt vastgesteld met een geknikte katheter in een lege blaas of met kathetergaatjes die geblokkeerd zijn met gel of slijm (van het inbrengen) of gaatjes die tegen de blaaswand zitten, beveelt de WG conform de GUP2002 aan om de initiële rustdruk pas vast te stellen als er $20-30 \mathrm{ml}$ vloeistof in de blaas is ingebracht [1]. Ook is het verstandig om beide meetkanalen kort te spoelen alvorens de initiële rustdruk wordt vastgesteld. De initiële rustdruk moet binnen de fysiologische grenzen zijn, zoals vermeld in de GUP2002, namelijk $30-40 \mathrm{cmH}_{2} \mathrm{O}$ bij een zittende volwassene [1].

\section{Dood signaal (nieuw)}

Een signaal dat geen kleine drukschommelingen weergeeft van ademen en of praten, en niet adequaat op persen, bewegingen of hoesten reageert, wordt gerapporteerd als een dood signaal (tijdens de meting, maar in een voorkomend geval ook achteraf).

De GUP2002 stelde: "In principe vereist een goed $\mathrm{p}_{\mathrm{det}}{ }^{-}$ signaal dat de $\mathrm{p}_{\text {ves }}$ en de $\mathrm{p}_{\mathrm{abd}}$ dezelfde fijne structuur- en signaalkwaliteit hebben, voorafgaand aan en tijdens het vullen, en tijdens en na de mictie." [1].

\section{Drukdrift (nieuw)}

Een continue langzame daling of stijging van de druk, die ('bio')fysiologisch onverklaarbaar is.

\section{Slechte druktransmissie (nieuw)}

Slechte druktransmissie bestaat als amplitudes van de hoestof persdruksignalen in het $\mathrm{p}_{\text {ves }}$ - en het $\mathrm{p}_{\mathrm{abd}}$-meetkanaal niet bijna gelijk zijn.

Opmerking: De WG geeft geen definitie van een limiet voor 'niet bijna gelijk'.

\section{Verlies van de katheter (nieuw)}

Als een katheter wordt verloren, wordt dit waargenomen als een plotselinge daling in de $p_{v e s}$ of $p_{a b d}$, meestal tot onder de $0 \mathrm{cmH}_{2} \mathrm{O}$. De ICS-beschrijving in de GUP2002 luidde [1]: '... als een plotselinge daling of stijging in ofwel het $\mathrm{p}_{\text {ves }}{ }^{-}$of het $\mathrm{p}_{\mathrm{abd}}$-signaal optreedt, is beweging, verstopping of verlies van een katheter daarvan de oorzaak'. Verlies van een katheter is meestal gewoon zichtbaar tijdens de test en zal eventueel correctie en/of herhaling van de test nodig maken. De term moet echter ook worden gebruikt bij de evaluatie na de test.

\section{Katheterspoelen (nieuw)}

Als een van de katheters wordt gespoeld, is tijdens de test een acute en sterke verhoging van de druk waarneembaar gedurende een of twee seconden, gevolgd door een onmiddellijke daling tot rustdruk. Na een zorgvuldig uitgevoerde set-up is katheterspoelen niet altijd nodig, maar in de GUP2002 wordt voorgesteld dat spoelen van de katheter gebruikt kan worden om - bij dood signaal na het inbrengen van de katheters - lucht, gel of urethrale slijm uit de meetgaatjes te verwijderen [1].

\section{Slangentik (nieuw)}

Een slangentik is een fenomeen dat waarneembaar is als er kortdurend, maar met een hoge frequentie, spikes zichtbaar zijn in de $p_{\text {ves }}$, $p_{\text {abd }}$, of in beide, waarbij er doorgaans ook pieken zichtbaar zijn in de $p_{\text {det. }}$ De oorzaak is stoten tegen of bewegen van de verbindingsslangetjes tussen de katheter en de externe drukopnemer.

\section{Pomposcillaties (nieuw)}

Pomposcillaties zijn zichtbaar als oscillaties met een stabiele frequentie en een kleine, maar constante amplitude. Ze komen voor als het drukkanaal de druk in het vulkanaal oppikt; eventueel als een systeem met twee katheters in de blaas wordt gebruikt, en de pomp is ingeschakeld. (Uitschakelen van de pomp zal leiden tot stoppen van de oscillaties.) 


\section{Hoestdrukpiek (nieuw)}

Een hoestdrukpiek is herkenbaar tijdens en na de test, bij evaluatie, als een positieve korte verandering van de druk, die wordt waargenomen in $\mathrm{p}_{\text {ves }}$ én $\mathrm{p}_{\mathrm{abd}}$.

\section{Urodynamische stresstest (nieuw)}

De term urodynamische stresstest wordt gebruikt voor iedere fysieke inspanning die de geteste persoon doet om de abdominale druk tijdens cystometrie te verhogen, met het doel urodynamische stress urine-incontinentie vast te stellen. De ICS heeft eerder een definitie van urodynamisch stress urine-incontinentie geformuleerd [5]. Bewijs betreffende een voorkeurstechniek van urodynamisch stresstests ontbreekt, of is tegenstrijdig, en de WG heeft geen verdere standaard voor de uitvoering van een urodynamische stresstest vastgesteld.

Opmerking: De provocatiemethode, de drukmeetkatheter (diameter) en de positie, de lekdetectiemethode, evenals het absolute of relatieve (dit is het percentage van de cystometrische capaciteit) intravesicale volume tijdens het testen, moeten worden gerapporteerd in een individueel verslag of in een studiecohort.

\section{Lekpuntdruk (nieuw)}

De term lekpuntdruk (LPP) is de druk (spontaan of uitgelokt) die geleid heeft tot verlies van vloeistof uit de blaas op het moment dat het verlies zichtbaar is buiten de urethra. De term kan ook worden gebruikt voor extra-urethraal urineverlies of verlies uit een stoma. Lekpuntdruk kan verwijzen naar buikpers (abdominal), hoest- of Valsalva-LPP of naar detrusor-LPP. Provocatie en plaats van drukopname ('type LPP') moeten worden gerapporteerd.

\section{Detrusoroveractiviteit bij hoesten (nieuw)}

Detrusoroveractiviteit wordt gemeld als het begin van een overactieve detrusorcontractie, met of zonder lekkage, die optreedt onmiddellijk na de hoestdrukpiek. Er is geen precieze definitie van detrusoractiviteit bij hoesten beschikbaar. Nogal eens wordt 'hoest-geïnduceerde (cough induced) detrusoractiviteit' gerapporteerd, maar omdat de precieze (patho)fysiologie (geïnduceerd?) en/of de relevantie ervan tot nu toe speculatief is gebleven, stelt de WG deze nieuwe term voor.

\section{Positieverandering (nieuw)}

Een verandering van de positie van de patiënt, actief of passief (bijvoorbeeld kantelen), is zichtbaar in de cystome- trie door een blijvende verandering van gelijke amplitude in zowel de $p_{\text {ves }}$ als de $p_{\text {abd. }}$.

Opmerking: Een verandering van de positie wordt (gemakkelijk) opgemerkt tijdens de test. Verandering van de positie moet worden gevolgd door aanpassing van de externe druksensoren, zodat de $\mathrm{p}_{\text {ves- }}$ en $\mathrm{p}_{\text {abd-waarden }}$ weer overeenkomen met de waarden van de druk vóór de verandering van positie. Een verandering van positie mag de $\mathrm{p}_{\text {det }}$ niet beïnvloeden. Het positieveranderingspatroon dient (ook) te worden herkend tijdens de beoordeling van de test na de cystometrie.

\section{Rectale contracties (nieuw)}

Rectale contracties zijn zichtbaar als tijdelijke stijgingen in $\mathrm{p}_{\text {abd, }}$, zonder synchrone verandering in de $\mathrm{p}_{\text {ves. }}$ Rectale contracties resulteren gewoonlijk in negatieve drukveranderingen van de $p_{\text {det. }}$ In de GUP2002 werd opgemerkt: 'Rectale contracties hebben meestal een lage amplitude en kunnen soms worden gevoeld door de patiënt' [1].

\section{Dalende $p_{\text {abd }}$ tijdens mictie (nieuw)}

Een daling in de $\mathrm{p}_{\mathrm{abd}}$ tijdens de mictie wordt gerapporteerd als de $\mathrm{p}_{\mathrm{abd}}$ daalt onder de voorgaande rustdruk, als gevolg van bekken- en buikspierontspanning.

Opmerking: De WG is van mening dat dit verschijnsel gevolgen heeft voor de druk-flowanalyse-uitkomst, omdat een daling in de $p_{a b d}$ invloed kan hebben op de $p_{\text {det. }}$. Deze observatie moet worden onderscheiden van katheterverlies (die meestal leidt tot een veel grotere daling van de druk).

\section{Persen (nieuw)}

Persen is waarneembaar als een tijdelijke stijging van zowel de $p_{\text {ves }}$ en de $p_{\text {abd. }}$. Persen kan samengaan met (een door de patiënt ondernomen) positieverandering (zoals de herpositionering van achteruitleunend naar rechtop), maar ook op zichzelf staand voorkomen.

Opmerking: Een korte abdominale drukpiek door persen, is achteraf mogelijk niet te onderscheiden van een verandering van de positie van de patiënt of van een hoest.

\section{Nacontractie (nieuw)}

Een nacontractie is een aanhoudende of nieuwe detrusorcontractie onmiddellijk na het einde van de mictie. Het is belangrijk op te merken dat een nacontractie optreedt na volledige lediging van de blaas; als er nog blaasinhoud (residu) is, wordt niet van nacontractie gesproken.

Opmerking: $\mathrm{Na}$ een druk-flowbepaling is altijd een hoestcontrole van de (intravesicale) katheterpositie vereist, om het patroon van verlies van de katheter of het ombui- 
gen van de kathetertip in de urethra tijdens de mictie te herkennen, zoals in de GUP2002 beschreven [1]. Deze hoestcontrole is bijzonder belangrijk als een toename van de $p_{\text {ves }}$ na de mictie is waargenomen om verwarring met nacontractie te voorkomen.

\section{De urodynamische grafieken en de verslaglegging van het urodynamisch onderzoek}

De WG beveelt aan dat, behalve de in de GUP2002 vermelde urodynamisch grafiek als tijdbasis [1], een 'drukflowplot van de mictie' moet worden gemaakt zoals beschreven in de ST1997 [7].

Voor de ICS-standaard urodynamisch test, adviseert de WG dus beide (nieuw):

- een ICS standaard urodynamische grafiek en

- een ICS standaard druk-flowplot (nieuw)

als vereiste elementen in het ICS-standaardverslag van het urodynamisch onderzoek bij iedere patiënt.

\section{Rapportage}

Bovendien raadt de WG rapportage aan als volgt: Door de persoon die de tests uitvoert, wordt behalve de technische betrouwbaarheid, geëvalueerd en hoe de tests de functie van de lage urinewegen hebben vastgelegd in vergelijking met wat de geteste persoon als gebruikelijk ervaart. Dit leidt tot een algehele beoordeling van de technische kwaliteit en van de klinische betrouwbaarheid van de test.

- Uroflowmetrie: omschrijving van de positie tijdens de mictie, de mate van drang (vóór de proef) en (achteraf) representativiteit, zoals gerapporteerd door de patiënt.

- Inbrengen van katheters: aanwezigheid van sensatie (of deze sensatie zich voordoet; of er sprake is van pijn), bekken- of adductoren spierverzet (defence) en, door de persoon die de katheterisatie heeft waargenomen, ongewone weerstand(en) of obstructie( $(s)$ tijdens het inbrengen.

- Positie tijdens cystometrie en tijdens de druk-flowstudie.

- Of de patiënt de blaasvullingssensaties en/of de urgentie en/of het urineverlies goed heeft kunnen waarnemen en/of aangeven.

- Volgens welke methode de urodynamische stresstest heeft plaatsgevonden (indien van toepassing).

- Druk-flow: representativiteit van de mictie zoals gerapporteerd door de patiënt.

- Aanvullende tests of metingen (indien van toepassing; geen verdere standaard).
- Representativiteit van de tests; om de gewoonlijk ervaren functie te reproduceren, zoals gerapporteerd door de patiënt.

- Vullingssensatie en de diagnose.

- Cystometrie (detrusor) drukpatroon en de diagnose.

- Druk-flow: de diagnose (vergeleken met uroflowmetrie) omvat:

- de blaasuitstroomfunctie of obstructie (en de methode van beoordeling);

- de detrusorcontractie (en de methode van beoordeling).

Deze items zullen de basis vormen voor een ICS standaard urodynamisch verslagsjabloon, dat in de nabije toekomst wordt ontwikkeld.

\section{Conclusie}

De WG van de International Continence Society heeft de standaard voor goed uitvoeren van urodynamisch onderzoek bijgewerkt. Deze op bewijs gebaseerde GUP2016 heeft voorwaarden en normen opgesteld voor de praktijk van urodynamische laboratoria in het algemeen, maar ook voor de (individuele, patiëntgebonden) praktijk van kwaliteitscontrole tijdens en na cystometrie en druk-flowstudie. Bovendien heeft de WG aanbevelingen opgenomen voor informatie voorafgaand aan de tests en voor informatie voor de patiënt ter voorbereiding. Verder gaf de WG anbevelingen voor de verslaglegging van het urodynamisch onderzoek. Op basis van eerdere ICS-standaardisatie en de wetenschappelijke literatuur, heeft de WG de praktijk van uroflowmetrie, cystometrie en druk-flowstudie verder uitgewerkt, in de hoop dat de implementatie van deze update van goed uitvoeren van urodynamisch onderzoek zal bijdragen aan verhoging van de kwaliteit van het klinisch urodynamisch onderzoek.

Open Access This article is distributed under the terms of the Creative Commons Attribution 4.0 International License (http:// creativecommons.org/licenses/by/4.0/), which permits unrestricted use, distribution, and reproduction in any medium, provided you give appropriate credit to the original author(s) and the source, provide a link to the Creative Commons license, and indicate if changes were made.

\section{Literatuur}

1. International Continence Society, Schäfer W, Abrams P, Liao L, et al. Good urodynamic practices: uroflowmetry, filling cystometry, and pressure-flow studies. Neurourol Urodyn. 2002;21(3):261-74.

2. Gammie A, Clarkson B, Constantinou C, et al. International continence society guidelines on urodynamic equipment performance. Neurourol Urodyn. 2014;33(4):370-9.

3. Rosier PF, Ridder D de, Meijlink J, et al. Developing evidencebased standards for diagnosis and management of lower 
urinary tract or pelvic floor dysfunction. Neurourol Urodyn. 2012;31(5):621-4.

4. Rosier PFWM, Schaefer W, Lose G, Goldman HB, Guralnick M, Eustice S, Dickinson T, Hashim H. International Continence Society Good Urodynamic Practices and Terms 2016: Urodynamics, uroflowmetry, cystometry, and pressure-flow study. Neurourol Urodyn. 2017;36(5):1243-60.

5. Abrams P, Cardozo L, Fall M, et al. The standardisation of terminology in lower urinary tract function: report from the standardisation sub-committee of the International Continence Society. Urology. 2003;61(1):37-49.
6. Rosier PFWM, Kuo H-C, De Gennaro M, International consultation on urologic disease, Cardozo. Urodynamic testing, chapter 6. In: Cardozo L, Khoury S, Wein A, redactie. Incontinence. 5e druk. Parijs: ICUD-EAU Paris; 2013. pag. 1895-955.

7. Griffiths D, Höfner K, Mastrigt R van, et al. Standardization of terminology of lower urinary tract function: pressure-flow studies of voiding, urethral resistance, and urethral obstruction. International Continence Society Subcommittee on Standardization of Terminology of Pressure-Flow Studies. Neurourol Urodyn. 1997;16(1):1-18. 